\title{
On the Role of Stirring on Microstructure and Ductility of Rheocast Al Alloys
}

\author{
QING ZHANG @i], ${ }^{1,3}$ STEFAN JONSSON,$^{2}$ and ANDERS E.W. JARFORS ${ }^{1,4}$ \\ 1.-School of Engineering, Materials and Manufacturing, Jönköping University, \\ 55111 Jönköping, Sweden. 2.-School of Industrial Engineering and Management, Materials \\ Science and Engineering, KTH Royal Institute of Technology, 10044 Stockholm, Sweden. \\ 3.—e-mail: qing.zhang@ju.se. 4.—e-mail: anders.jarfors@ju.se
}

Two alloys containing different $\mathrm{Mg}$ contents have been used to study the combined effect of stirring and oxidation on microstructure and ductility. The results show that intensive stirring can sufficiently disperse the $\alpha$-Al particles and enable better liquid feeding during solidification and consequently reduce the porosity. The morphology of the oxides is determined by the amount of both $\mathrm{Mg}$ and stirring. With lower $\mathrm{Mg}$ content, the oxides present as oxide films, which can be broken up during stirring. In alloy with higher Mg content, the oxides exist as particles with numerous cracks, and the particle size increases slightly after stirring. In the Magsimal 59 alloy, due to the presence of large clusters of pores in the fracture surface, the influence of the small oxide particles on the ductility is negligible. In contrast, in the 42000 alloy, large oxide films on the fracture surface are correlated with the ductility.

\section{INTRODUCTION}

Semisolid metal (SSM) casting has been widely used in automotive and electronic industries to achieve weight reduction. ${ }^{1}$ As one of the variations of SSM, the RheoMetal ${ }^{\mathrm{TM}}$ process enables the production of slurry within a 30-s duration and can be included in a high-pressure die casting (HPDC) route without significant process adjustments, making the process a promising alternative for industrial application. ${ }^{2}$ However, the application of SSM is often limited by semisolid deformationinduced casting defects such as macrosegregation ${ }^{3}$ and large pores. ${ }^{4}$ Dahle et al. ${ }^{5}$ reported that with the progress of the solidification process, an inhomogeneously distributed yield strength, due to the variation of the solid fraction distribution, plays a decisive role in the semisolid deformation and thus the formation of either significant segregation or porosity, depending on whether there is sufficient time for melt to compensate shrinkage during the solidification process. Furthermore, the clusters formed in the slurry-making process strongly increase the slurry yield strength locally, leading

(Received June 29, 2021; accepted September 8, 2021; published online October 4, 2021) to the formation of large defects. ${ }^{6}$ Therefore, to control the formation of these large defects, it is critical to optimise the distribution of the yield strength in a slurry. In general, the yield strength is heavily dependent on the solid fraction, particle morphology and particle distance, ${ }^{7,8}$ and one effective approach to alter the particle distance is applying shearing to the slurry because of the Reynolds' dilatancy. ${ }^{9,10}$ Therefore, in the RheoMetal $^{\text {TM }}$ process, it is possible to adjust the stirring method to obtain dispersed particles and globular particles in the slurry and, consequently, optimised casting microstructures.

Another critical issue in SSM is the introduction of oxides during slurry preparation. Due to the high affinity of oxygen to Al, oxidation on the surface of $\mathrm{Al}$ alloy melts is inevitable. The oxides formed at the surface are readily entrained into the casting, especially under intensive stir. However, many studies have reported that intensive stirring can break up the oxide films into fine particles, which act as potent sites for nucleation during solidification to reduce the grain size. ${ }^{11}$ Zuo et al. ${ }^{12}$ reported that intensive melt shearing eliminates bifilms, improves the wettability of the dispersed oxide particles and reduces hydrogen content, resulting in much lower porosity. Besides, as a primary 
alloying element in $\mathrm{Al}$ alloys, magnesium affects the oxidation mechanism, and thus the structure and morphology of the resultant oxides are altered. ${ }^{13}$

In this study, two different stirring set-ups were used to study the influence of the stirring on the slurry quality in terms of particle morphology, particle distribution, formation of defects and their relationship with ductility. Two $\mathrm{Al}$ alloys with significantly different $\mathrm{Mg}$ contents were investigated to evaluate the effect of $\mathrm{Mg}$ on the oxidation behaviour under various stirring conditions.

\section{EXPERIMENTAL}

\section{Alloys}

The materials used were EN AC-42000 (AlSi7Mg) and Magsimal 59 (AlMg5Si2Mn). The chemical compositions of the alloys, measured with a Spectro Max CCD LMXM3 optical emission spectrometer, are listed in supplementary Table SI (refer to online supplementary material).

\section{Slurry Preparation and Casting}

The alloys were melted using a resistance furnace with a $200-\mathrm{kg}$ capacity and held at $700^{\circ} \mathrm{C}$. SSM castings were produced using the RheoMetal ${ }^{\mathrm{TM}}$ process, as shown in Fig. 1a. For slurry preparation, the enthalpy exchange material (EEM) was first cast around a 12-mm-diameter stainless steel rod, which was inserted into the EEM at $10 \mathrm{~mm}$ depth by pouring the melt into a copper mould with a cylindrical cavity $(40 \mathrm{~mm}$ diameter and $100 \mathrm{~mm}$ depth) in the centre and with internal water-cooling channels. After casting, the EEM was sectioned to obtain $6 \%$ of the total shot weight. Next, the rod and EEM were preheated up to $200^{\circ} \mathrm{C}$ in an electrical resistance air circulation oven. For the slurry fabrication, around $1.3 \mathrm{~kg}$ of superheated melt was ladled from the furnace and allowed to cool. When reaching a given temperature $\left(\sim 35^{\circ} \mathrm{C}\right.$ superheat, $650^{\circ} \mathrm{C}$ for 42000 alloy and $660^{\circ} \mathrm{C}$ for Magsimal 59, respectively), the preheated EEM, rotating at about $1100 \mathrm{rpm}$, was immersed into the melt. The slurry fabrication process was assumed to be complete when the turbulence on the slurry surface stopped, which took about $18 \mathrm{~s}$. Subsequently, the slurry was poured into the shot sleeve of a 50-tonne vertical pressure die casting (VPDC) machine to produce a component in the shape of a flat tensile bar with 3 $\mathrm{mm}$ thickness. The die temperature was controlled by a PolyTemp HTF 300 heater set at a constant temperature of $175^{\circ} \mathrm{C}$. The first-stage plunger speed was $\sim 0.4 \mathrm{~m} / \mathrm{s}$. The speed increased to $\sim 1 \mathrm{~m} / \mathrm{s}$ during the second stage. The switch point was set as the slurry top face reached the cavity of the bar. The switch point was set to $113 \mathrm{~mm}$ travel distance from the starting position. Before semisolid casting began, five shots were made as high pressure die casting to heat the machine and die. This also set the thermal conditions in the shot sleeve and die cavity. (a)

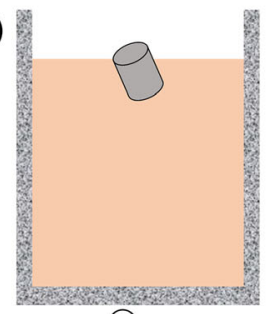

(1)

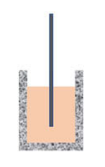

(2)

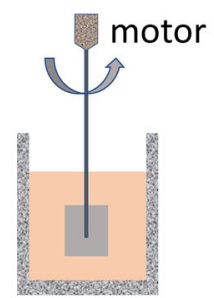

(3)

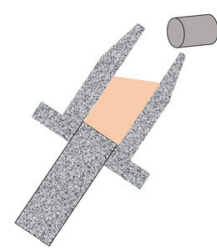

(4)

(b)
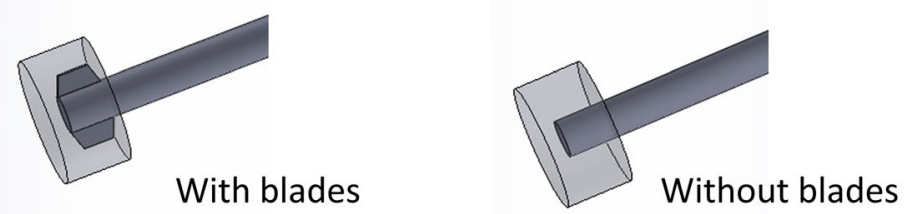

(c)

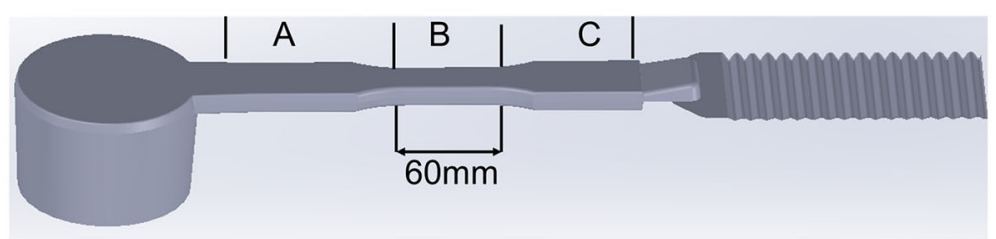

Fig. 1. Schematic illustration of the slurry fabrication process. (a) RheoMetal ${ }^{\mathrm{TM}}$ process steps: (1) ladling, (2) casting the enthalpy exchange material (EEM), (3) stirring in the solid EEM to make the slurry, (4) pouring the slurry into the shot chamber. (b) Standard RheoMetal ${ }^{\text {TM }}$ processing rod and EEM (right) and intensive stirring set-up with wings added to the rod cast into the EEM body (left); (c) casting shape and different zones analyzed in the work. A: grip start; B: gauge; C: grip end. 
In the current study, a standard set-up for normal stirring (with a shear rate of $37 \mathrm{~s}^{-1}$ ), right side in Fig. 1b, and a non-standard set-up for intensive stirring (with a shear rate of $156 \mathrm{~s}^{-1}$ ), left in Fig. 1b, were used to study the role of stirring. For the nonstandard set-up, the rod had two SiC-coated blades, allowing for intensive shearing of the slurry.

In addition, three more ladles of slurry, prepared by normal and intensive stirring, respectively, were quenched directly after the slurry fabrication process to determine the quality of the slurry in terms of contiguity, which indicates the level of dispersion of the particles.

\section{Tensile Testing}

Five tensile bars from each casting condition were tested, and no surface treatment/machining was performed on the samples. The tensile tests were performed according to the SS-EN ISO 6892-1:2016 standard using a Zwick/Roell Z100 machine with a constant strain rate of $0.00025 \mathrm{~s}^{-1}$ up to offset yield strength determination and subsequently with a faster strain rate of $0.002 \mathrm{~s}^{-1}$ until fracture. A LaserXtens extensometer was used to measure the elongation.

\section{Microstructure Characterization}

Metallographic samples were prepared using standard metallographic procedures. The castings in section $\mathrm{B}$ with a length of $60 \mathrm{~mm}$, shown in Fig. 1c, were cut evenly into 12 pieces along the transverse cross-section to determine the area fraction of pores by optical microscopy (Olympus GX71F). The whole area of pores on each section surface was measured and then divided by the cross-section area. To better characterise the primary $\alpha$-Al particles with optical microscopy, $10 \%$ $\mathrm{NaOH}$ reagent was used to etch the polishing surface. The quantitative image analysis method ${ }^{14}$ was used to measure the solid fraction. To determine the solid fraction in the surface layer and central regions, two optical micrographs were captured from the centre and surface on each transverse cross-section, respectively. Image analysis was then performed using a ImageJ software to measure the area of the solid phase. Afterwards, the solid fraction was calculated using the equation: ${ }^{14}$

$f_{\mathrm{s}}=\frac{\text { Number of pixels that belong to phase being analyzed }}{\text { Total area of pixels in the image }}$

To calculate the contiguity of the quenched slurry from both stirring conditions, ten micrographs, from both normal stirring and intensive stirring, were taken with optical microscopy randomly from the quenched slurries.

The fracture surfaces from tensile test samples were analysed with scanning electron microscopy (JEOL JSM-7001F SEM) equipped with energydispersive x-ray spectroscopy (EDS) to evaluate the fracture mode and area fraction of both oxides and porosity in the fracture surface.

\section{RESULT}

\section{Quality of the Slurry}

Figure 2 shows the distribution of the solid particles in the quenched slurry of the Magsimal 59 alloy. More and larger liquid zones are present in the quenched slurry under normal stirring, indicating a less homogeneous distribution of the solid particles. The contiguity of the slurry is analyzed to show the degree of particle dispersion in the slurry. A drop in the contiguity within samples under intensive stirring was observed, indicating that intensive stirring helps to disperse the particles better, which is similar to Reynolds' dilatancy ${ }^{9,10}$ in densely packed granular materials. ${ }^{15}$

\section{Microstructure and Porosity Observation}

Figure 3 shows the typical microstructures of the 42000 and Magsimal 59 alloys under normal stirring and intensive stirring conditions after a light etch, using a $10 \% \mathrm{NaOH}$ solution. In both alloys, the samples under normal stirring exhibit larger and more pores; see supplementary figure S1. Pores were more frequent in the Magsimal 59 alloy under both normal and intensive stirring conditions. As summarised in supplementary figure S2, under the application of intensive stirring, the global porosity for the 42000 and Magsimal 59 alloys reduces from $0.12 \%$ and $0.20 \%$ to $0.03 \%$ and $0.14 \%$, respectively. Figure 3 shows a more homogeneous distribution of the primary $\alpha$-Al grains in the intensive stirring samples. Primary $\alpha$-Al grains disperse relatively evenly within the cross-section after intensive stirring.

In contrast, $\alpha-\mathrm{Al}$ particles concentrate in the central region accompanied by numerous local eutectic-rich zones in the samples subjected to normal stirring, which is in good agreement with the solidification distribution shown in supplementary table SII. More obvious shear bands are observed in the samples under intensive stirring, and the normal stirring reduces the distance between shear bands and the casting surface, especially for 42000 , where no shear bands are present. Figure $3 \mathrm{~b}$ shows that the shear bands in 42000 are located right next to the casting surface.

\section{Tensile Test}

The effect of the stirring intensity on the ductility of castings is shown in Fig. 4. Different influences are found for the two alloys. The 42000 alloy presents a significant drop with increased intensity, whereas the Magsimal 59 alloy indicates a slight rise, although engulfed by uncertainty. The distinct difference in the deviation of the alloys between normal and intensive conditions is probably due to the manual operation in the slurry-making process. 


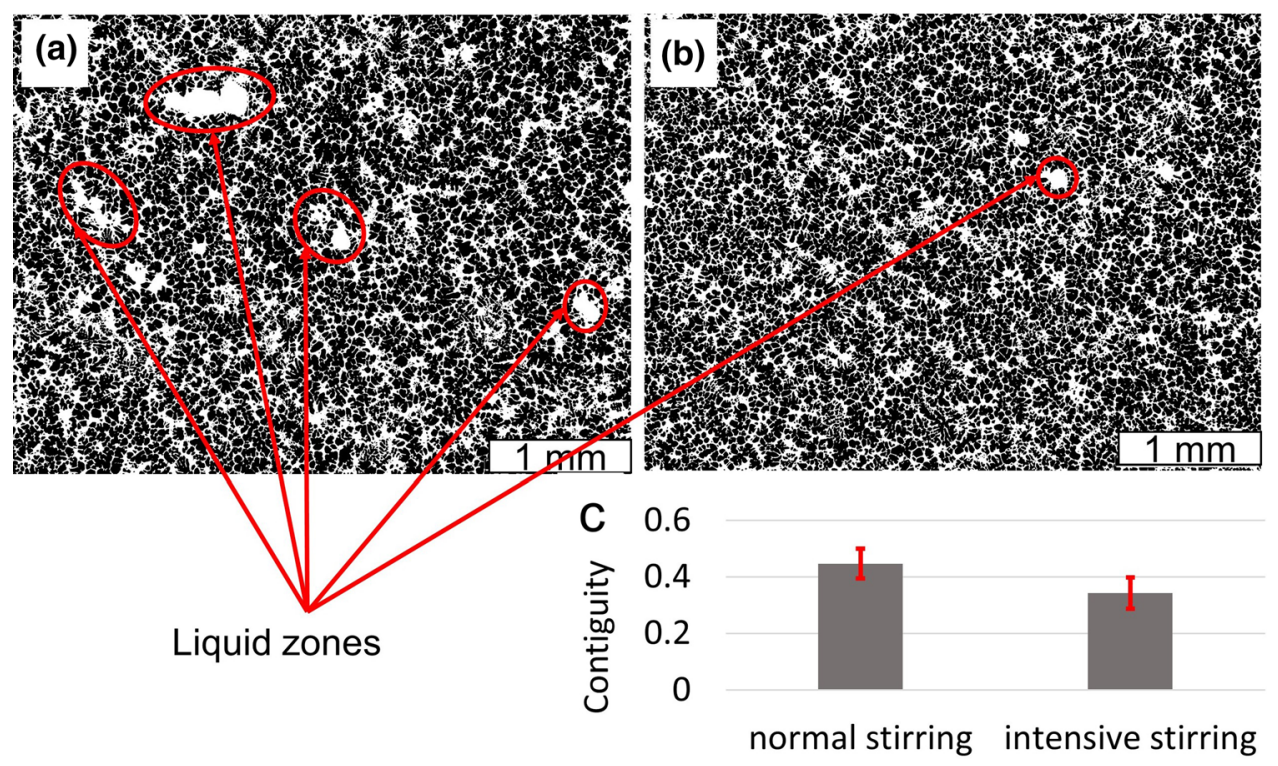

Fig. 2. Microscopy of quenched Magsimal 59 slurry under normal stirring (a) and intensive stirring (b); calculated contiguity (c).

During the slurry-making process, to sufficiently stir the slurry, the melt ladle was moved in a circle around the rotating EEM. At the end of the slurrymaking process, the EEM was dissolved and the naked stirrer was exposed to the slurry. In this case, the stir of the normal stirrer (cylinder rod) can be negligible. However, for the intensive stirrer (with two blades), the effect of the stirring depends on the extent of the movement of the ladle. Insufficient manual movement will dramatically reduce the effect of the intensive stirring, resulting in the increase of the porosity. This is supported by the lesser difference deviation for 42000 alloy, as its elongation is mainly determined by the oxides (see "Combined Effect of $\mathrm{Mg}$ and Stirring on the Formation of Oxides" section).

Figure 5 shows the typical defects found on the fracture surface after tensile testing. Both pores and oxides can be found for the two alloys. It can be noticed that the pores in 42000 are much smaller than those in Magsimal 59, as shown in Fig. 5a and b. Figure 5c and d shows the typical morphology of the oxides in the fracture surface of the 42000 and Magsimal 59 alloys, respectively. In the 42000 alloy, both young oxide films and oxide particles are found (Fig. 5c). In Magsimal 59, more discrete blocky oxides are found without any typical features of oxides films (Fig. 5d). The atomic ratio from EDS indicated that the oxide particles in Fig. 5c and $d$ are $\mathrm{MgAl}_{2} \mathrm{O}_{4}$, which is in agreement with the results of Refs. 13 and 16. Furthermore, the average oxide size is shown in supplementary figure S3. As seen, the oxides on the fracture surface are more significant for the 42000 alloys than for the Magsimal 59 alloy, regardless of the stirring condition.

\section{DISCUSSION}

\section{Effect of Stirring on the Quality of Slurry and Resultant Defects of Castings}

The quality of the slurry can be further understood by considering the formation of the slurry, including the dissolution of the EEM and the nucleation in the melt. ${ }^{2}$ Considering the homogeneity of the particle distribution, the dissolution of EEM is important. At the later stage of the slurry preparation, the partially melted EEM collapses and drops into the slurry, forming solid clusters and a consequent local high liquid fraction region, as shown in Fig. 2. Similar EEM behaviour was reported in Ref. 6. Afterwards, the semisolid deformation under shearing plays a critical role in the dispersion of the particles. In high solid fraction regions, with abundant large clusters, the particles connect, forming a solid network. The network restricts the particle movements, and to move, the particles need to push each other apart, increasing the space between them. ${ }^{10,17,18}$ Compared to normal stirring, the intensive stirring (presenting a higher Reynolds number shown in supplementary information, providing more vigorous shearing) provides sufficient shearing across the slurry to efficiently separate the particles, dispersing more local clusters by semisolid deformation.

The most visible difference between normal stirring and intensive stirring, related to the observed defects, is the reduced porosity for intensive stirring (supplementary figure S2). Gas entrainment would result in a random distribution of pores. In the current casting, the pore distribution is located in the centre, where the solid fraction is high (supplementary Table SII). This strongly suggests that the porosity is dominated by shrinkage porosity. During solidification, the volumetric shrinkage in the liquid 

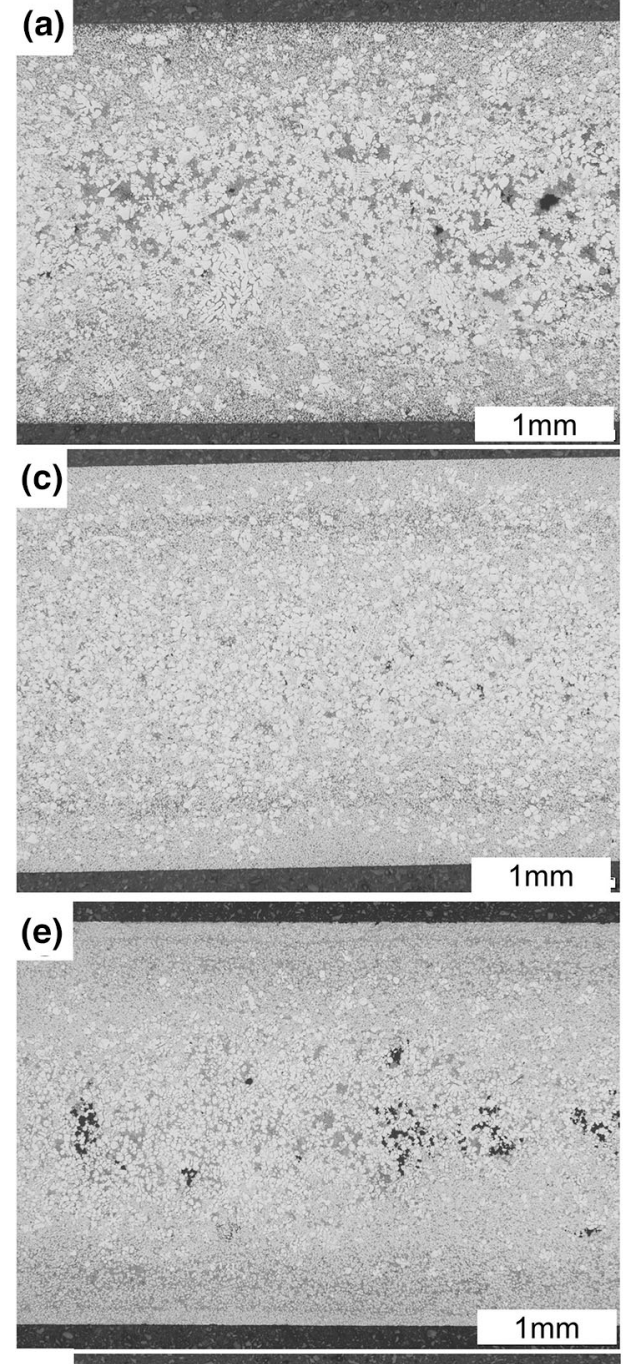

(g)

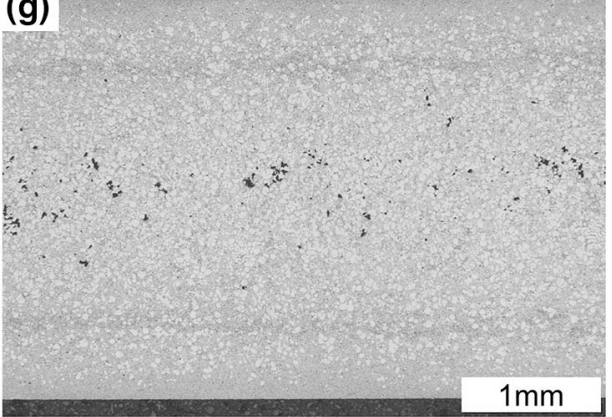

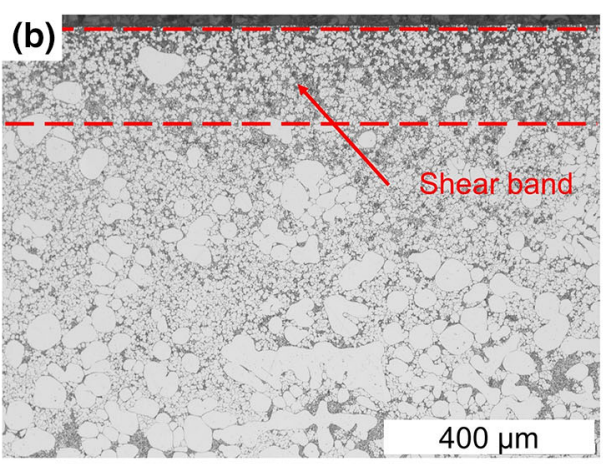
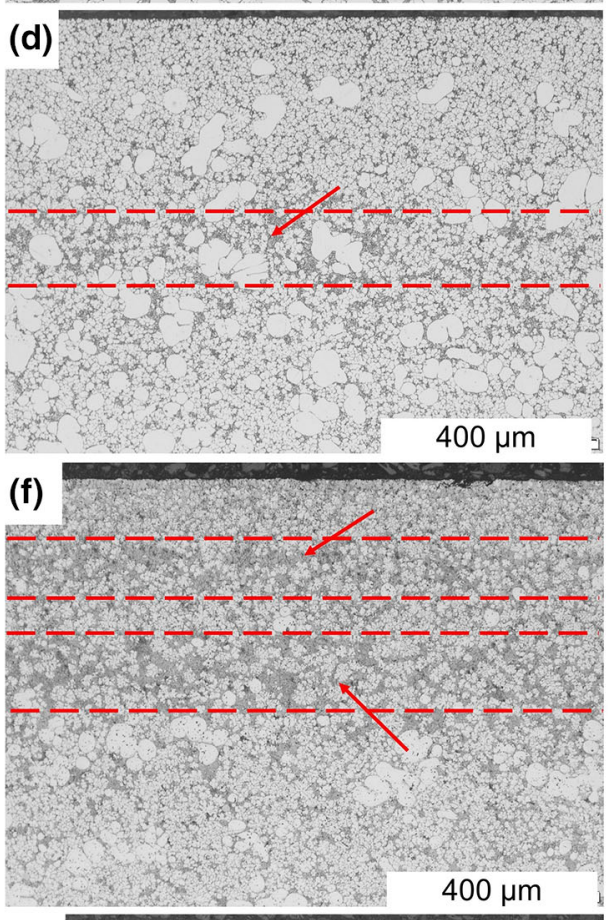

(h)

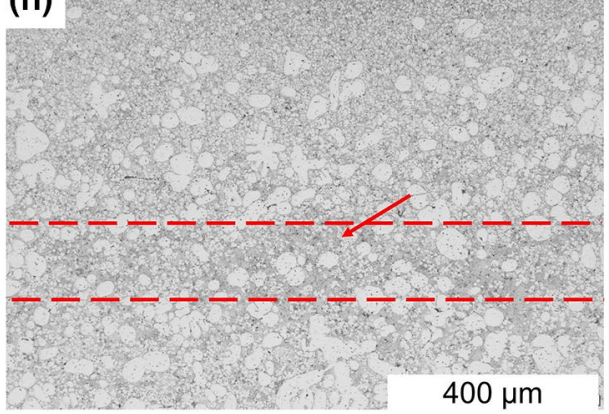

Fig. 3. Optical micrographs of etched 42000 (a-d) and Magsimal 59 (e-h), respectively. (a, b) and (e, f) After normal stirring and (c, d) and (g, h) after intensive stirring. Red dashed lines indicate shear bands (Color figure online).

region requires more liquid metal to be fed to the solidifying region to compensate for the volume change. For normal stirring, the surrounding solid clusters form enclosed liquid regions, consequently blocking the feeding channel.

Furthermore, the larger enclosed liquid region in castings with normal stirring exacerbates the severity of inefficient feeding, resulting in larger pores, as shown in Fig. 3. However, under intense shearing, the structures in the slurry break and become activated through Reynolds dilatancy, decreasing the contiguity to improve the feeding ability. In addition, the presence of more frequent and larger pores in Magsimal 59 is likely to be attributed to the higher liquid fraction (supplementary table SII), which aggravates the volume change during solidification. Besides, previous work ${ }^{19}$ proposed one possible mechanism of porosity formation. Intensive 
stirring could effectively break up the structure and reduce the viscosity in the slurry, making it possible for the hydrogen gas, which could precipitate at

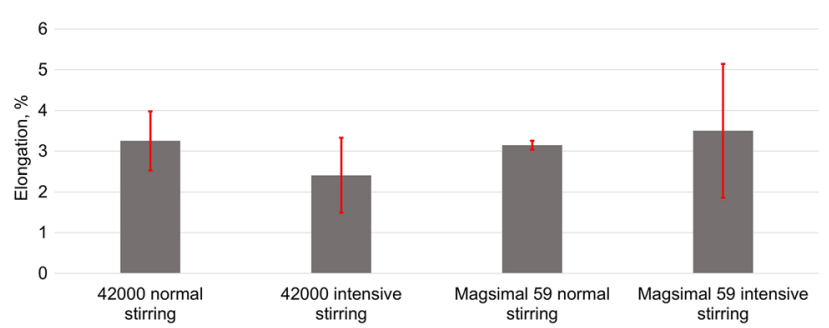

Fig. 4. Elongation of the 42000 and Magsimal 59 alloys under various stirring conditions. various phases in alloys, ${ }^{20,21}$ to escape from the local high solid fraction regions. Thus, the degassing step, through intensive stirring, causes the reduction of the porosity in the intensive stirring samples. However, this proposed mechanism needs further hydrogen content measurement for confirmation.

Another visible difference between normal and intensive stirring is the formation of shear bands. The formation of the shear bands is related to the mechanical behaviour of the partially solidified microstructure when shear stresses are developed during the filling process. ${ }^{5}$ The slurry can be divided into three regions with different mechanical behaviours by the dendritic coherency point $\left(f_{\mathrm{s}}^{\mathrm{ch}}\right)$ and maximum packing solid fraction $\left(f_{\mathrm{s}}^{\mathrm{pk}}\right)$. The $f_{\mathrm{s}}^{\mathrm{ch}}$
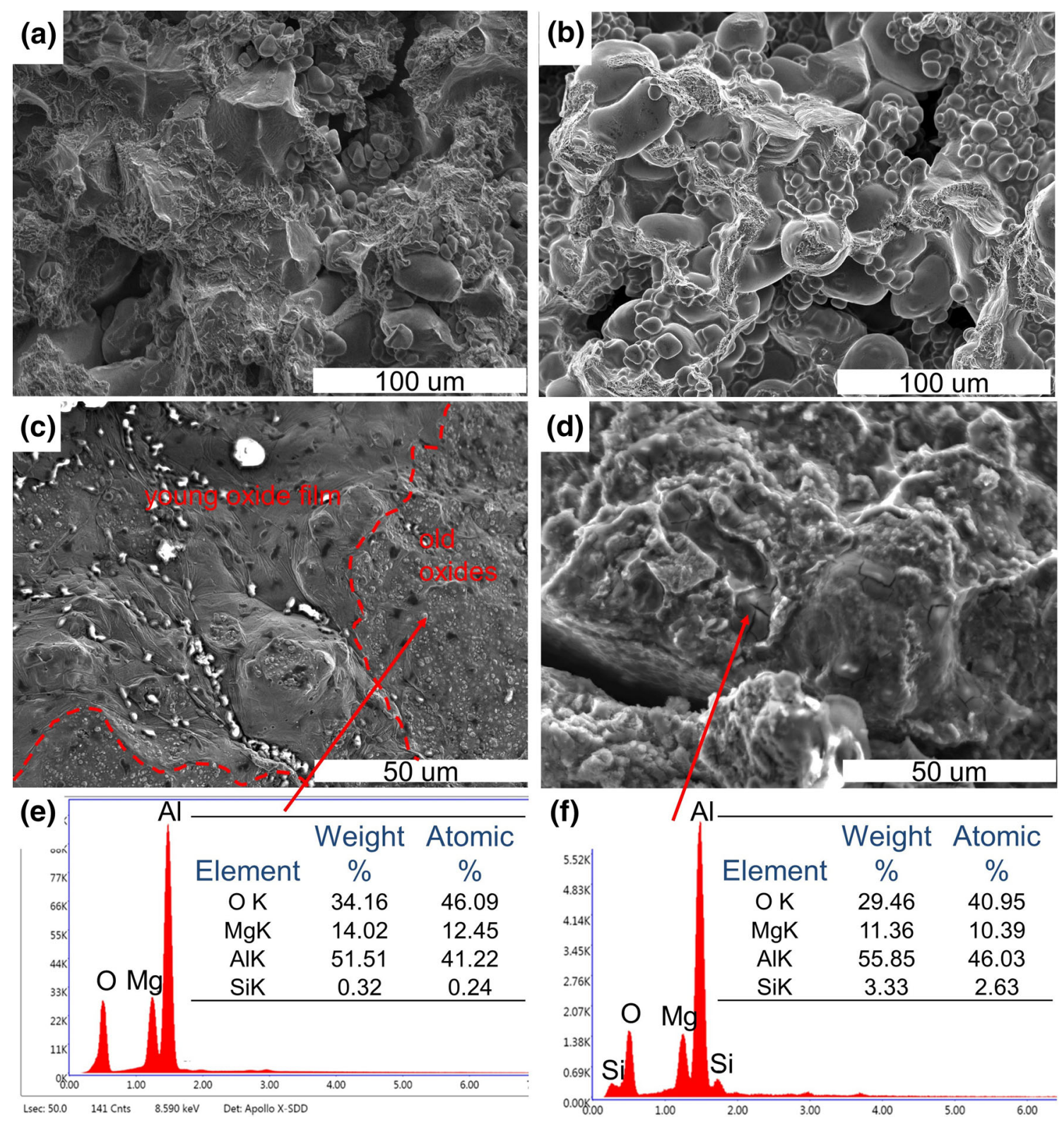

Fig. 5. Micrograph of the typical defects in fracture surfaces of the 42000 (left column) and Magsimal 59 alloys (right column). (a), (b) Porosity and (c), (d) oxides on the fracture surface; (e), (f) corresponding EDS spectra. Red dashed line in (c) is a demarcation line of the film oxide (upper left) (Color figure online). 
marks the point of impingement of the dendrites and is where strength development begins. When the solid fraction is greater than $f_{\mathrm{s}}^{\mathrm{pk}}$, the strength increases at a faster rate. ${ }^{22}$ Both these points are strongly dependent on the morphology of particles/dendrite aggregates, and the typical values of $f_{\mathrm{s}}^{\mathrm{ch}}$ and $f_{\mathrm{s}}^{\mathrm{pk}}$ range around $0.1-0.5$ and $0.3-0.74$, respectively. For the 42000 alloy, when casting with normal stirring, the solidified clusters reveal large dendritic structures which interlock with each other, so that the $f_{\mathrm{s}}$ in the central region $(\sim 0.37)$ is likely to reach $f_{\mathrm{s}}^{\mathrm{pk}}(0.3-0.74)$. Thus, the central slurry will behave as a solid. Contrarily, the regions close to the casting surface will possess a much lower yield strength, as more liquid concentrate $\left(f_{\mathrm{s}} \sim 0.17\right)$ is there because of particle migration. ${ }^{23}$ Consequently, the semisolid deformation initiates next to the casting surface, resulting in the formation of a shear band just underneath the casting surface, as shown in Fig. 3b, while for casting with intensive stirring, the uniformly dispersed particles possess a small and regular structure, leading to significantly lower yield strength in the central region, regardless of the comparable $f_{\mathrm{s}}(\sim 0.36)$. With progress of solidification, the melt next to the surface solidifies ahead of the central region because of greater undercooling near the surface. The strength increases simultaneously, minimising the variation of the yield strength across the surface and central regions. When the strength of the solidified surface region is greater than the strength of the adjacent inner region, the shear bands are formed farther away from the casting surface. They form where the strength is the lowest, i.e., between the solidified surface and the central zone (with a higher solid fraction), as shown in Fig. 3d. In Magsimal 59, the same structures are observed, namely, shear bands located relatively close to the surface (normal stirring) and shear bands located far away from the surface (intensive stirring). However, the sensitivity of the solid fraction in relation to the temperature change for Magsimal 59 is higher than that for 42000, as shown in Fig. 6. Especially in the $0-0.5$ range of the solid fractions, the temperature difference is $34^{\circ} \mathrm{C}$ and $45^{\circ} \mathrm{C}$ for the Magsimal 59 and 42000 alloy, respectively. During the filling process, $f_{\mathrm{s}}$ of both alloys falls in the interval of $0-0.5$ (supplementary table SII). The increase of the solid faction near the casting surface for Magsimal 59 is quicker because of the sensitivity to temperature. Furthermore, the relatively higher temperature for the slurry of Magsimal 59 leads to a steeper temperature gradient near the surface, which also drives the solidification. Therefore, the semisolid deformation-induced shear bands are likely to be formed during both the filling process and the following feeding process under intensive pressure, leading to two layers of shear bands under each surface, as shown in Fig. 3e and $f$.

\section{Combined Effect of $\mathrm{Mg}$ and Stirring on the Formation of Oxides}

Due to the high affinity of $\mathrm{Mg}$ to oxygen, the $\mathrm{Al}$ alloys containing $\mathrm{Mg}$ oxidise more readily than $\mathrm{Mg}$ free $\mathrm{Al}$ alloys. For the $\mathrm{Mg}$ containing $\mathrm{Al}$ alloys, the details of the oxidation behaviour of molten $\mathrm{Al}-(2-$ $12 \%) \mathrm{Mg}$ alloys can be described by two consecutive steps, $\mathrm{Mg}+1 / 2 \mathrm{O}_{2} \rightarrow \mathrm{MgO}$ followed by $\mathrm{MgO}+2 \mathrm{Al}+3 /$ $2 \mathrm{O}_{2} \rightarrow \mathrm{MgAl}_{2} \mathrm{O}_{4}$. This is reasonable as thermodynamically $\mathrm{MgAl}_{2} \mathrm{O}_{4}$ is a more stable compound than $\mathrm{MgO} .{ }^{24}$ Therefore, at sufficient $\mathrm{Mg}$ content, the final oxides would be $\mathrm{MgAl}_{2} \mathrm{O}_{4}$, which is in good agreement with the current study, as shown in Fig. 5d. The Pilling-Bedworth ratio $\left(R_{\mathrm{PB}}\right)$ is the ratio of the volume of the elementary cell of a metal oxide to the volume of the elementary cell of the corresponding metal. Based on the $R_{\mathrm{PB}}$, it can be judged whether the metal is likely to passivate in dry air by creating a protective oxide layer. When the $R_{\mathrm{PB}}<1$, the formed oxide films are likely to be broken, while continuous films form when the $R_{\mathrm{PB}}$ falls within 12 . $\mathrm{MgO}$ with an $R_{\mathrm{PB}}$ of $0.84,{ }^{25,26}$ therefore revealing a film with numerous cracks. Considering that the formation of $\mathrm{MgAl}_{2} \mathrm{O}_{4}$ is a product of two consecutive reactions, the $\mathrm{MgAl}_{2} \mathrm{O}_{4}$ also presents as small films with numerous cracks. This feature is confirmed in Fig. 5.

$\mathrm{Li}$ et al. ${ }^{16}$ reported that $\mathrm{MgAl}_{2} \mathrm{O}_{4}$ exists as discontinuous oxide films in dilute $\mathrm{Al}-\mathrm{Mg}$ alloys $(\mathrm{Mg}<$ 1 wt.\%). The stirring could effectively break up and disperse the discontinuous oxide films as oxide particles. However, in the alloys containing high amounts of $\mathrm{Mg}(\mathrm{Mg}>1 \mathrm{wt} . \%)$, the oxides exist as naturally dispersed discrete particles, and the stirring then promotes the growth of the oxide particles instead because of the readily enhanced kinetic conditions for mass transport. This is confirmed in supplementary figure S3. In Magsimal 59, where the $\mathrm{Mg}$ content is much higher than $1 \mathrm{wt} \%$, the oxide particle size under intensive stirring shows an increasing tendency compared to the normal stirring condition. The oxide films in 42000 alloys also show a tendency to size increase for intensive stirring conditions, which, however, contradicts Li

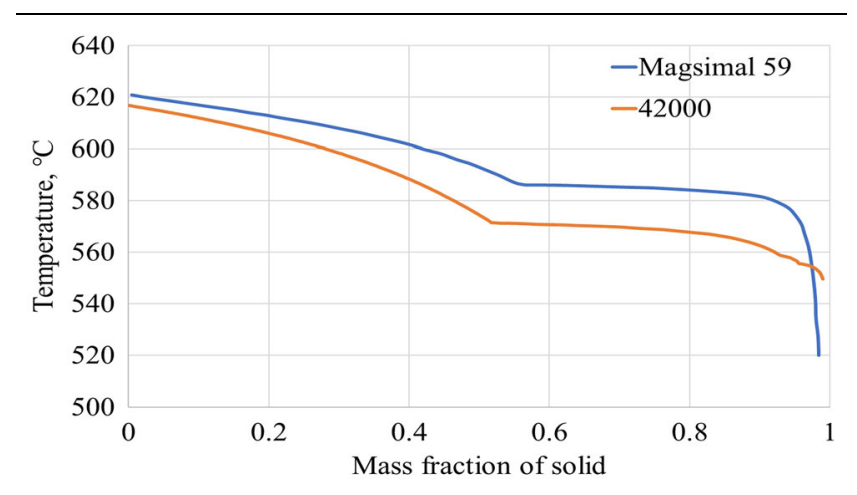

Fig. 6. Relationship between temperature and solid fraction by weight for Scheilean-Gulliver solidification of 42000 and Magsimal 59 calculated using Thermo-Calc software. 
et al., ${ }^{16}$ where the intensive stirring was effective for particle refinement in alloys with an $\mathrm{Mg}$ content $<1$ wt.\%. This increase of the oxide size in our work could arise from the filling process, where intensive shearing is absent to break up the oxide films. For the intensive stirring slurry, the slurry presents a better malleability due to lower contiguity and more dispersed particle distribution. This leads to turbulence during the filling process and consequently to increased oxidation forming larger young oxide films, as shown in Fig. 5c and supplementary figure S4. The dimensionless Reynolds number (Re) is usually used to measure the degree of turbulence. The transition from quiescent laminar flow to turbulent flow occurs in the range of $2300<$ $\operatorname{Re}<4000 .{ }^{27}$ In the present work, Re equals 1195 and 2633 for normal stirring and intensive stirring slurries during the filling process, respectively. (The calculation of these values is detailed in supplementary information.) Therefore, for intensive stirring, turbulence could be predominant during the filling process resulting in the formation of large oxide films.

\section{Effect of Oxides and Porosity on the Elongation}

It is reported that the tensile ductility shows little or no correlation with the bulk porosity. In contrast, the decrease of elongation correlates with the fracture surface porosity. ${ }^{28}$ To analyse the effects of both oxides and porosity, the elongation was plotted versus the size of the largest oxides on the fracture surface versus the fracture surface porosity for both alloys, as shown in Fig. 7 .

Figure $7 \mathrm{a}$ illustrates a clear relation between the largest oxides and ductility for the 42000 alloy, while no apparent correlation between fractographic porosity and elongation can be found (Fig. 7b). This indicates that the largest oxides in the fracture surface determine the ductility of the 42000 alloy. This is logical as the largest size of the oxides varies from 0.1 to $0.9 \mathrm{~mm}$, and the largest defects become relevant to the ductility when $>0.2 \mathrm{~mm} .^{29}$

As for Magsimal 59 alloy, as the largest oxides mainly fall $<0.2 \mathrm{~mm}$, no correlation between the ductility and largest oxides can be found, as shown in Fig. 7c. However, the fracture surface porosity for the 42000 alloy is almost twice as high as for the Magsimal 59 alloy, and Fig. 7d shows a slight tendency of decreased elongation with increased porosity. However, the dispersion of the results suggests that other factors, such as pore morphology in the fracture surface, may have an influence. In this study, the normal stirring produces particle clusters and coarse shrinkage pores with few and narrow bridges across the porosity zone, as shown in supplementary figure S5 (a), leading to poor ductility. Intense stirring, on the other hand, activates the particles sufficiently to produce a slurry of dispersed particles and small pores surrounded by eutectic. Thick bridges form across the porosity zone, as shown in supplementary figure S5 (b), with enhanced ductility.

Consequently, the largest effective pore size in the fracture surface, free of eutectic bridges, was evaluated. When the elongation was plotted against this quantity (Fig. 8), a clear correlation could be observed. This indicates that the largest effective pores, rather than the fractographic porosity, determine ductility.

Based on these results, the predominant factors on the ductility are oxides for the 42000 alloy and effective pores for the Magsimal 59 alloy, respectively. The influence of these factors is determined by both the oxidation during the slurry preparation process and porosity formation during the solidification process.

\section{CONCLUSION}

A series of experiments have been performed to evaluate the effect of stirring on the microstructure and ductility of two different $\mathrm{Al}$ alloys containing different amounts of Mg. Samples with different casting structures have been studied with respect to porosity, oxides and shear bands. The effect of pores and oxides on the ductility is clarified.

Intensive stirring activates the slurry more efficiently, resulting in a dispersed and homogeneous distribution of $\alpha-\mathrm{Al}$ particles, improving the shrinkage compensation during solidification. As a result, fewer and smaller pores form.

Intensive stirring introduces more oxygen into the melt and forms more oxides in the samples. However, the effect of the stirring on the final morphology of the oxides depends on the Mg content in the alloys. In the 42000 alloy, with lower $\mathrm{Mg}$ content, the oxides are presented as oxide films, which can be broken up under stirring. In Magsimal 59 alloy, with higher $\mathrm{Mg}$ content, oxide particles with numerous cracks are dispersed across the samples. The oxide particle size in this alloy can be increased slightly during stirring.

In the 42000 alloy, the largest oxides on the fracture surface after tensile tests vary from 0.1 to $0.9 \mathrm{~mm}$ and relate to the ductility, whereas the pores on the fracture surface are too small to affect the elongation significantly. In contrast, there is no correlation between the oxides on the fracture surface and ductility in the Magsimal 59 alloy due to the formation of small oxides (usually $<0.2 \mathrm{~mm}$ ) in the Mg-rich alloy. Due to the lower solid fraction in this alloy, coarser pores and eutectic bridges between the pores form. As a result, the effective largest pores, rather than the overall porosity in the fracture surface, determine the ductility. 

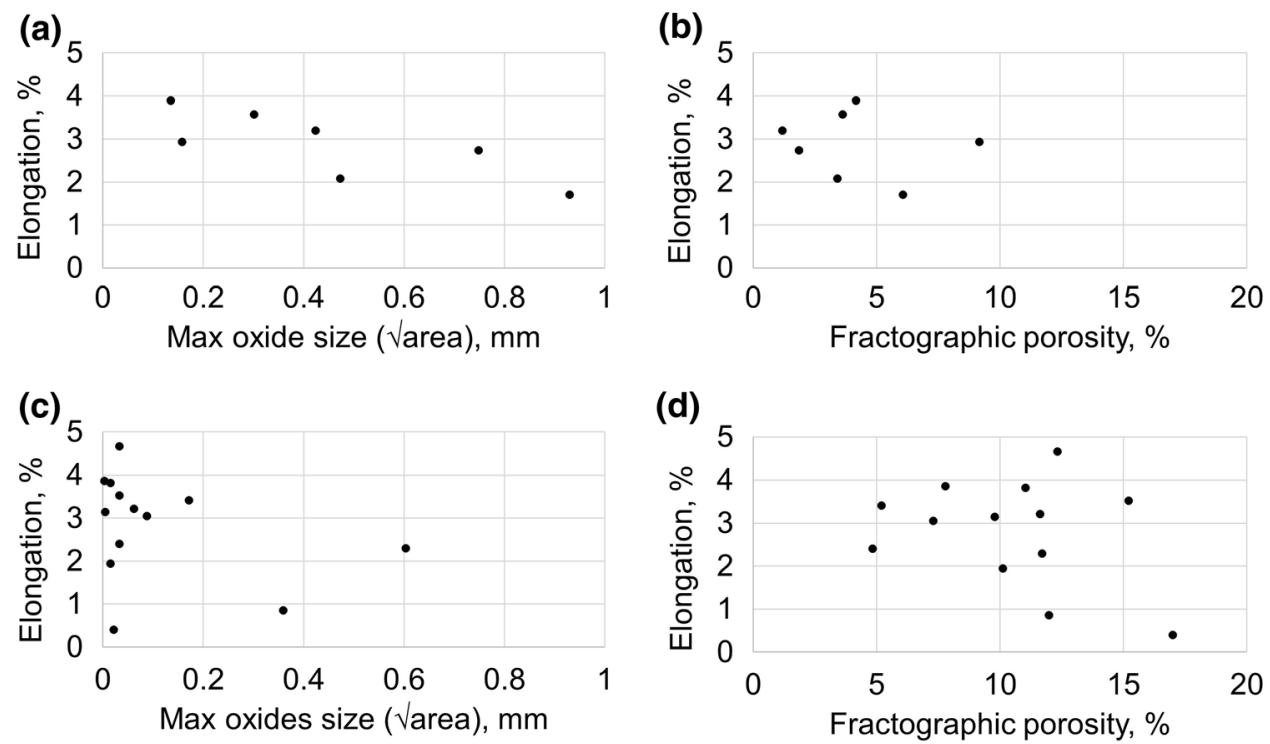

Fig. 7. Elongation to fracture as a function of (a) and (c) maximum oxide size on the fracture surface and (b) and (d) fractographic porosity. (a, b) and (c, d) 42000 and Magsimal 59 alloys, respectively.

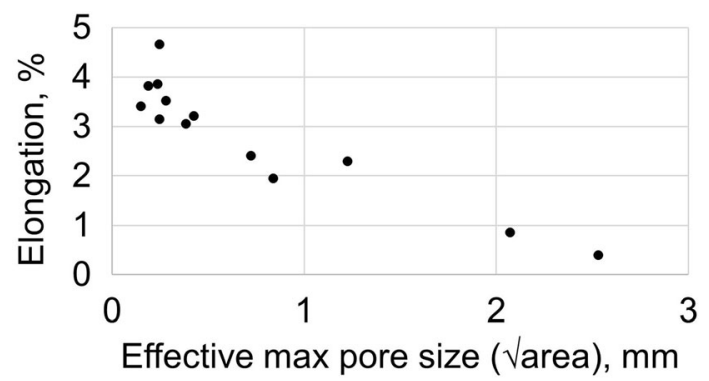

Fig. 8. Elongation versus largest effective pores on fracture surface of Magsimal 59 alloy.

\section{ACKNOWLEDGEMENTS}

The authors are thankful for the financial support from Scania CV, Volvo Car Corporation and Comptech AB. Jorge Santos and Vasile Lucian Diaconu are also acknowledged for their assistance with the casting experiment.

\section{AUTHOR CONTRIBUTIONS}

QZ: Conceptualisation, Methodology, Investigation, Writing - original draft, review and editing. SJ: Supervision, Review and editing. AEWJ: Conceptualisation, Methodology, Supervision, Review and editing, Funding acquisition.

\section{FUNDING}

Open access funding provided by Jönköping University. Funding was provide by vinnova (Grant No. 2018-02831).

\section{CONFLICT OF INTEREST}

The authors declare that they have no conflict of interest.

\section{OPEN ACCESS}

This article is licensed under a Creative Commons Attribution 4.0 International License, which permits use, sharing, adaptation, distribution and reproduction in any medium or format, as long as you give appropriate credit to the original author(s) and the source, provide a link to the Creative Commons licence, and indicate if changes were made. The images or other third party material in this article are included in the article's Creative Commons licence, unless indicated otherwise in a credit line to the material. If material is not included in the article's Creative Commons licence and your intended use is not permitted by statutory regulation or exceeds the permitted use, you will need to obtain permission directly from the copyright holder. To view a copy of this licence, visit http://creativecommons.org/licenses/by/4.0/.

\section{SUPPLEMENTARY INFORMATION}

The online version contains supplementary material available at https://doi.org/10.1007/s11837021-04905-6.

\section{REFERENCES}

1. A.E.W. Jarfors, J. Zheng, L. Chen, and J. Yang, Solid State Phenom. 285, 405. (2019).

2. O. Granath, M. Wessén, and H. Cao, Int. J. Cast Met. Res. 21, 349. (2008).

3. C.P. Chen, and C.Y.A. Tsao, Acta Mater. 45, 1955. (1997).

4. S. Otarawanna, H.I. Laukli, C.M. Gourlay, and A.K. Dahle, Metall. Mater. Trans. A Phys. Metall. Mater. Sci. 41, 1836. (2010).

5. A.K. Dahle, and D.H. StJohn, Acta Mater. 47, 31. (1998). 
6. J. Santos, A.E.W. Jarfors, and A.K. Dahle, Solid State Phenom. 256, 222. (2016).

7. M. Modigell, and M. Hufschmidt, Solid State Phenom. 116117, 587. (2006).

8. A. Moll, and M. Modigell, Int. J. Mater. Form. 3, 779. (2010).

9. O. Reynolds, Lond. Edinb. Dublin Philos. Mag. J. Sci. 20, 469. (1885).

10. C.M. Gourlay, and A.K. Dahle, Nature 445, 70. (2007).

11. Z. Fan, Y. Wang, Z.F. Zhang, M. Xia, H.T. Li, J. Xu, L. Granasy, and G.M. Scamans, Int. J. Cast Met. Res. 22, 318. (2009).

12. Y. Zuo, H. Li, M. Xia, B. Jiang, G.M. Scamans, and Z. Fan, Scr. Mater. 64, 209. (2011).

13. Y. Wang, H.T. Li, and Z. Fan, Trans. Indian Inst. Met. 65, 653. (2012).

14. L. Wojnar, K.J. Kurzydłowski, and J. Szala, Metallogr. Microstruct., 403. (2004).

15. W. Powrie, Soil Mechanics (CRC Press, Boca Raton, 2018).

16. H.-T. Li, Y. Wang, and Z. Fan, Acta Mater. 60, 1528. (2012).

17. B. Meylan, S. Terzi, C.M. Gourlay, M. Suéry, and A.K. Dahle, Scr. Mater. 63, 1185. (2010).

18. C.M. Gourlay, B. Meylan, and A.K. Dahle, Acta Mater. 56, 3403. (2008).
19. A.E.W. Jarfors, Q. Zhang, and S. Jonsson, Metals (Basel) 10, 1560. (2020).

20. H. Toda, T. Hidaka, M. Kobayashi, K. Uesugi, A. Takeuchi, and K. Horikawa, Acta Mater. 57, 2277. (2009).

21. J. Campbell, Castings 1, 54. (2003).

22. A.K. Dahle, and L. Arnberg, JOM 48, 34. (1996).

23. M. Law, C.N. Hulme-Smith, T. Matsushita, and P.G. Jönsson, J. Manuf. Mater. Process. 4, 51. (2020).

24. K.C. Vlach, O. Salas, H. Ni, V. Jayaram, C.G. Levi, and R. Mehrabian, J. Mater. Res. 6, 1982. (1991).

25. C. Xu, and W. Gao, Mater. Res. Innov. 3, 231. (2000).

26. B. Hallstedt, Calphad Comput. Coupling Phase Diagr. Thermochem. 31, 292. (2007).

27. A. E. W. Jarfors and S. Seifeddine, Handb. Manuf. Eng. Technol. 2, 309 (2013).

28. C. Do Lee, Mater. Sci. Eng. A 464, 249. (2007).

29. A. Niklas, S. Orden, A. Bakedano, M. da Silva, E. Nogués, and A.I. Fernández-Calvo, Mater. Sci. Eng. A 667, 376. (2016).

Publisher's Note Springer Nature remains neutral with regard to jurisdictional claims in published maps and institutional affiliations. 